\title{
INTEGRATING BALANCED SCORECARD AND SIMULATION MODELING TO IMPROVE EMERGENCY DEPARTMENT PERFORMANCE IN IRISH HOSPITALS
}

\author{
Khaled Ismail \\ Waleed Abo-Hamad \\ Amr Arisha \\ 3S Group, School of Management \\ Dublin Institute of Technology (DIT) \\ Dublin 2, Dublin, Ireland
}

\begin{abstract}
In the healthcare sector, there is a requirement for innovative solutions in managing the high levels of complexity and uncertainty within Emergency Departments (EDs). Simulation modeling is currently seen as a competent means of analyzing EDs, which allows changes effects to be understood and predicted more easily. The Balanced Scorecard (BSC), well-known performance management concept, has become a steering method in approaching new improvement cycles. This paper presents a methodology that integrates BSC and simulation modeling to improve the performance of ED in a University Hospital in North Dublin. BSC design began with understanding patient's needs, ED activities, as well as training and development programs. Then a detailed simulation model was developed and integrated with the BSC to provide a comprehensive decision support system. This integrated model can be used for evaluation of various decisions in emergency area. The developed integrated model is also a tool for improvement.
\end{abstract}

\section{INTRODUCTION}

Healthcare is a significant industry that embraces numerous resources and contributes to the progress of nations. Healthcare organizations continually aim to provide tangible reforms that can lead to better service quality and patient care experiences. However, they are facing considerably growing pressures including; increasing service costs, service demand, and quality expectations. In an Irish context, the health Service Executive (HSE) addressed in its strategy (HSE 2008) urgent courses of action to bring real and sustained reforms to Irish healthcare services. Meeting these pressures and managing the growing gap between the needs and costs of healthcare is a real challenge to decision makers. There is a need for innovative solutions and applications that are capable of understanding the system dynamics and increase efficiency, while taking resources utilization and process rationalization into consideration.

Hospitals represent a significant part of healthcare service providers (almost $60 \%$ of the capacity). $\mathrm{ED}$ is considered as the frontline defense in managing the flow of patients into the hospitals. Owing to the fact that number of patients arrive at ED usually exceed the physical capacity of the waiting rooms, hence there is a critical problem for ED managers to solve (McCaig and Burt 2004). Waiting time is non- value adding activity that always leads to poor patient satisfaction at different levels. Besides, overcrowding has dramatic consequences that include higher mortality rates for patients (Richardson 2006). Crowding involves the patients waiting for ED admission, being monitored in non-treatment areas (corridors), and those waiting to be admitted in the hospital (inpatient). Those patients utilize resources in non-treatment areas and their waiting times exceed reasonable periods (Schneider et al. 2008) and with higher arrival rate, the problem can get worse (Miller, Ferrin, and Szymanski 2003). Therefore, performance of EDs is regarded as a significant factor in the Irish healthcare reforms. Based on this premises, a scheme is presented by the HSE in 2007 (HSE 2007) to reward hospitals that maintain high performance levels. To support continual improvement that leads to reduce the pressure on EDs, HSE has set in the scheme a target of less than 6 hours to overall patient waiting time within the ED. 
Although the results showed some improvements, the assessment to the target figure at many Irish hospitals is yet unsatisfactory (HSE 2009).

Senior healthcare leaders struggle to develop the right strategy to reduce the gap between the rising service costs and the growing demand for higher quality levels. However, to develop and apply a management system that can coordinate diverse staff categories toward the strategy direction is becoming more pivotal for strategy implementation (Voelker, Rakich, and French 2001). The BSC, pioneered by Kaplan and Norton (1992), is a systematic methodology that uses strategy-linked leading and lagging performance measures and actions for planning and implementing an organization's strategy (Kaplan and Norton 2001). Among the main benefits of applying the BSC are; 1) an excellent way for communicating and gaining insights into strategic initiatives, key objectives, and actions among decision makers and other staff, 2) a comprehended and easy scheme for compelling the improvement cycles as it facilitates working on analysis, weakness, and potentials for improvements. With many successful implementations at different organizations, BSC is considered as a popular model and effective means for performance management and strategy execution. Furthermore, the BSC concept has been modified and successfully developed at different types of healthcare organizations (Zelman, Pink, and Matthias 2003). As a pilot study, BSC has been implemented in an ED of a hospital in Taiwan, including nine performance indicators of four perspectives, resulted in improvements at all performance indicators (Huang et al. 2004). Due to budget constraints, large number of variables, and high levels of uncertainties and dynamics associated with the ED system, BSC alone will give a limited guide for ensuring planned performance in the ED. Simulation is a powerful tool used to capture the complexity and dynamic features of ED processes.

Simulation models have been proven to be an excellent and flexible tool for modeling such kinds of complex environment (Arisha and Young 2004). Few studies in the literature used simulation to model the operation of ED using patient's waiting time and throughput time as the main target service quality. Patient waiting time within the ED is analyzed using modeling and simulation (Takakuwa and Shiozaki 2004). A simulation model is a flexible tool that can be used to simulate the effect of different possible ED settings on patient waiting time (Sinreich and Marmor 2004). The impact of staff scheduling can also be investigated using simulation and modeling (Spry and Lawley 2004). Moreover, multi-performance indicators can easily be measured using a simulation model, as stated by Swisher and Jacobson (2002). A simulation model is also an effective tool for testing the effect of different resource allocation schemes, which is crucial for efficient utilization of resources within the ED (Centeno et al. 2003). Simulation modeling used to examine staff scheduling impact on overall utilization and burnout issues related to over-utilized staff (Thorwarth, Arisha, and Harper 2009). Aforementioned studies show that modeling and simulation is currently seen as a competent tool for EDs performance analysis, which allows the effects of actions and changes to be understood and predicted more easily.

This paper presents a methodology that integrates the BSC concept and simulation modeling capabilities to provide rational and effective improvement for ED performance. The proposed methodology is tested on a real-world case study of an emergency department of one of the leading hospitals in the Republic of Ireland.

\section{AN EMERGENCY DEPARTMENT IN IRISH HOSPITAL}

A leading university hospital in north Dublin has an emergency department which serves about 45,000 - 50,000 patients annually. The outline patient flow in ED is shown in Figure 1.

Patients arrival has two patterns; self-arrival or ambulance. In case of ambulance arrival, registration and triage processes can be dropped or completed en route to hospital. The ED uses a 5-colour triage system: Blue, Green, Yellow, Orange and Red. Blue represents patients with minor or least severe injuries and Red signals to severe emergency cases (i.e. life is at risk). The first assessment of a patient is provided by a triage nurse, a triage category is then labeled for the patient. Based on that category, the patient is then directed to the next process (Figure 2).

This allocation scheme causes a delay for triage nurse to see the next patient. Availability of resources (cubicles, trolleys, seats) and/or searching for support to allocate the patient are the main reasons for that delay. Moreover, the triage category can be altered by the doctor later on. Resulting in over-crowding and longer waiting times for patients due to wrong decisions made by the triage nurse. Triage nurses can also be delayed due to interruptions by patients in the waiting room asking about their turn for diagnosis or complaining about longer waiting time. Doctors tend to examine patients with a higher priority first. Finding the patients location by a doctor can be a time consuming 
Ismail, Abo-Hamad and Arisha

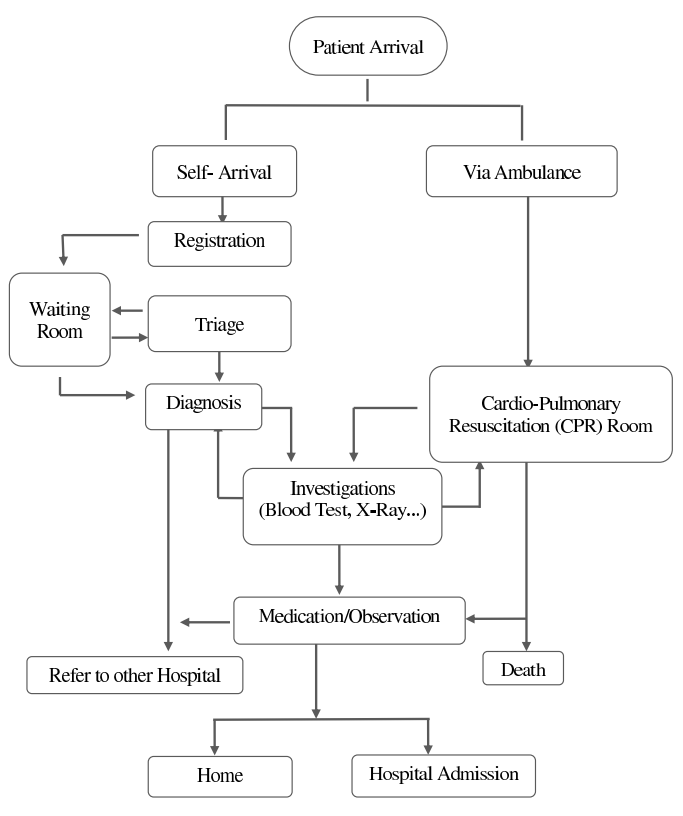

Figure 1: High level of patient flow.

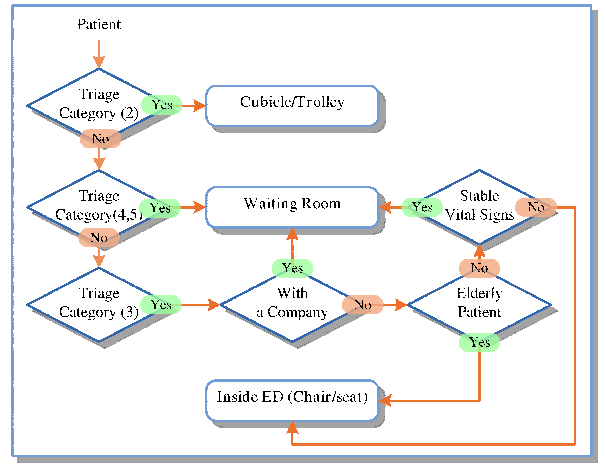

Figure 2: Patient allocation according to triage category.

process, this is due to over-crowding inside the ED that leaves no space for incoming patients and random allocation for them. This necessitates the overlapping of ED operational /treatment areas such as the cubicles of Area-I and Area-II (Figure 3).

Such dynamic environment of ED affects how resources are allocated for each treatment area, resulting in under or over utilization of resources (staff, equipments, etc). If a patient is not in a cubicle or a proper place for examination, then searching for a proper place for examination is another issue that doctor faces, resulting in increasing of patient treatment time and increasing in subsequent patients' waiting time. After examination, a doctor identifies the required investigations and laboratory tests if necessary. If laboratory results are available, a doctor searches again for the patient for a final diagnosis decision. A doctor follows up more than one patient simultaneously, 3 - 5 patients every 4 hours, depending on the doctors experience. At peak times, finding a proper examination place takes longer than usual. Besides, shortage in computer terminals for recording/updating patient record detains doctors for a short length of time. Moreover, if a nurse is not available, a doctor brings pain killers or fluid drip stands himself. Obviously, controlling the patient waiting time or patient journey time (cycle time) inside the ED is a very challenging task, especially at peak times, which is usually unexpected due to high variability in patient arrival patterns. It is very challenging to estimate the utilization of resources in such a complex dynamic environment. Intuition and experience are not 


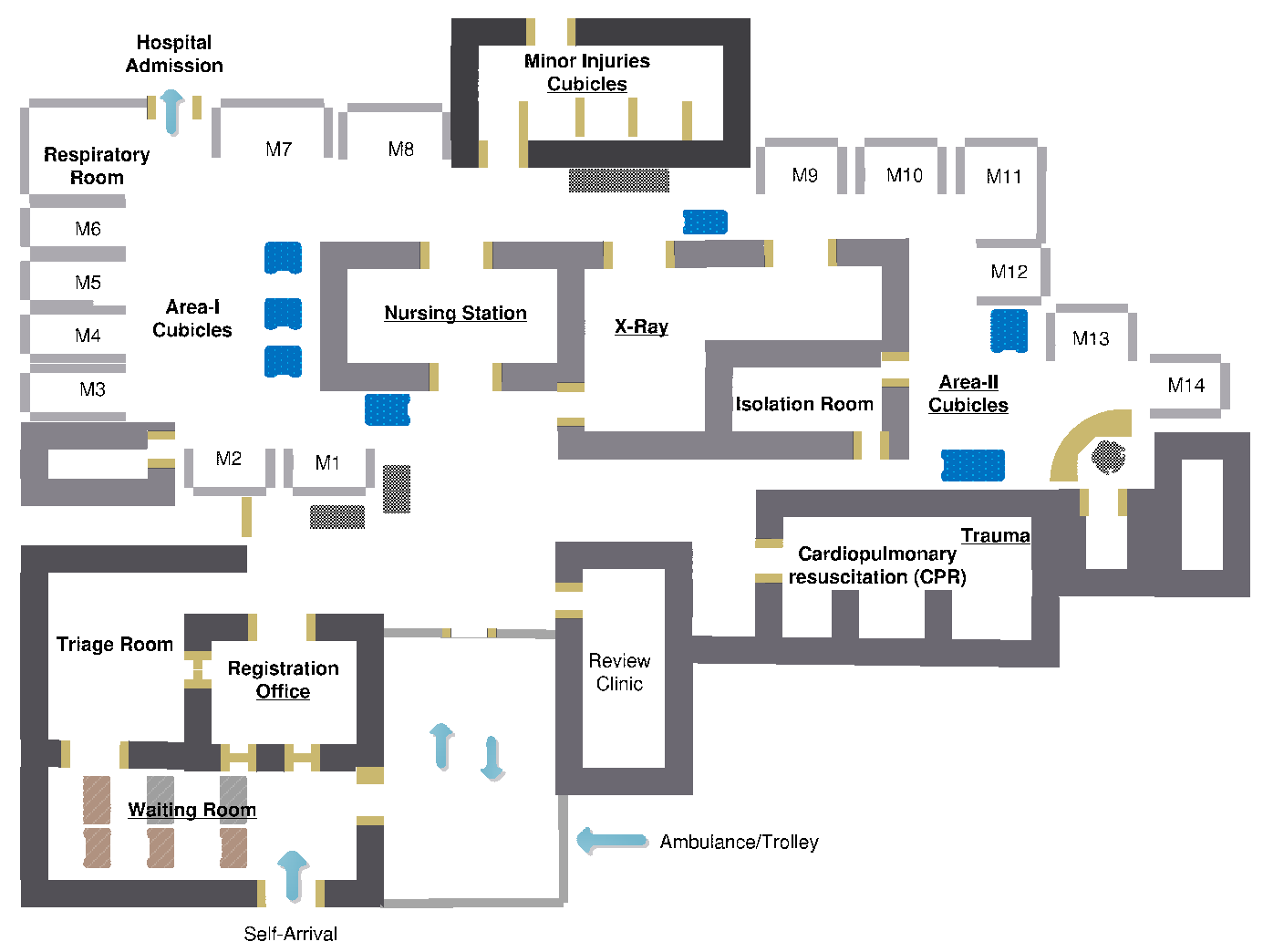

Figure 3: ED layout and operational areas.

enough for ED managers to monitor and improve performance. Potential decision managing tools are needed to support managers decisions by giving more insights into internal operational processes and resources usage of the ED, with the goal to provide sustainable improvement. The next section will discuss such mechanisms and how they can be integrated to form a convenient and powerful framework for ED decision makers.

\section{THE PROPOSED INTEGRATED MODEL}

Planning, analyzing, and evaluating the performance of ED are key elements for setting a comprehensive framework to support continual improvement. As a start, to transform objectives into a set of actions, managers need to put a proper measure and set a realistic and achievable target for each objective. Integrating simulation modeling with BSC will help to find bottlenecks within the EDs. Moreover, it supports decision makers, managers, and staff to conduct the appropriate analysis and corrective actions. Since initiatives can be evaluated using a simulation approach and the corresponding impact will be shown on the performance scorecard, more initiatives will be anticipated and decisions will be more accurate. The integration between BSC and simulation is shown in Figure 4. This proposed integration will be used at the ED case study to evaluate the impact of a set of different scenarios on the performance.

\subsection{Simulation Model}

\subsubsection{Data Collection Phase}

The results of the model are only as good as the input data. Therefore, for a successful simulation model, data acquisition is indispensable. In the case study, the hospital managers have provided historical data about patients arrival rate as well as medical staff. Due to some gaps in the recording data, close contact and collaboration with the staff was performed in order to measure the process 


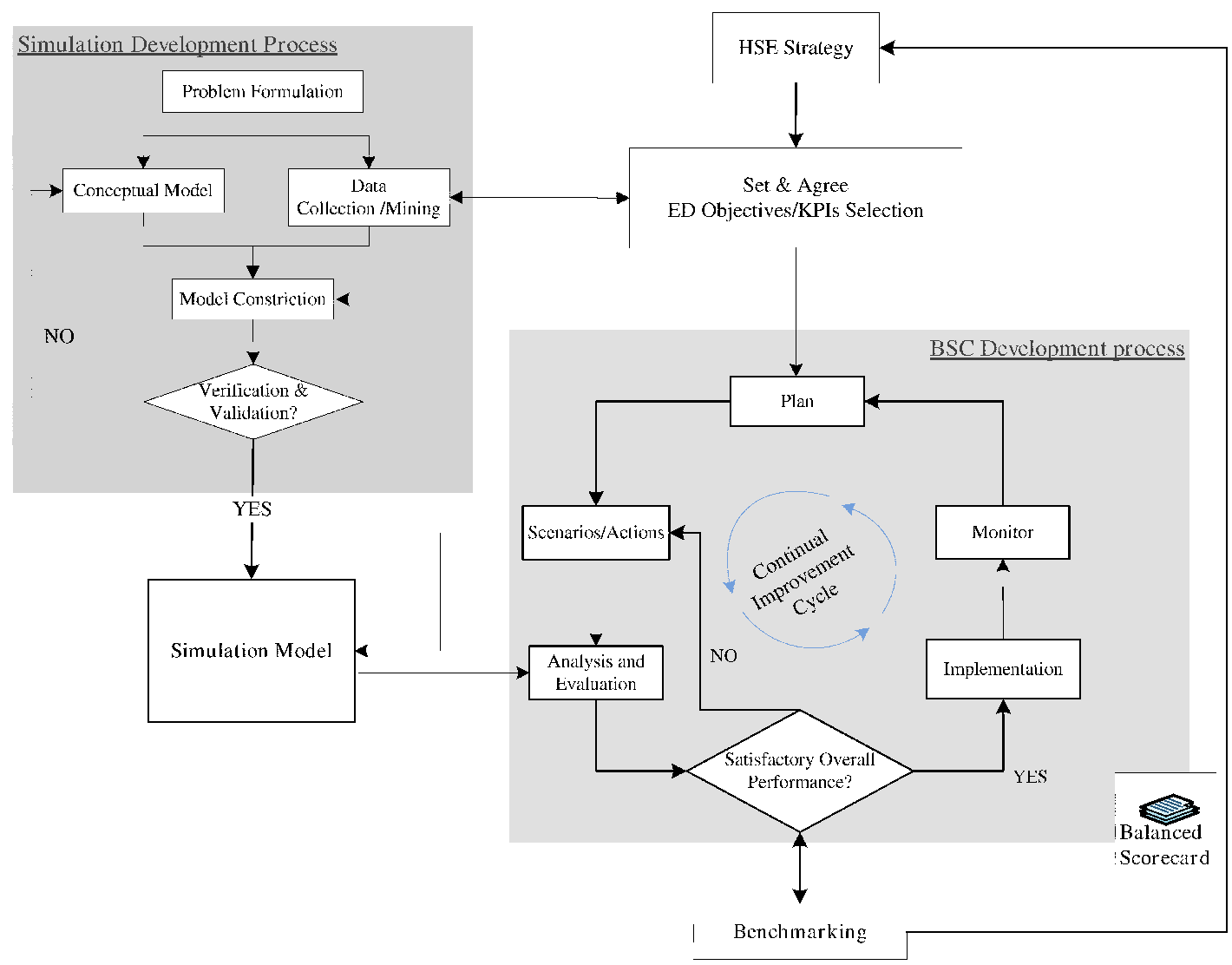

Figure 4: BSC and simulation modeling integration.

times. Computer records, direct observations, and staff interviews were the main sources for collected data. Two arrival modes of patients are identified: patients arrive by either ambulance (20\%) or as self-arrival patients $(80 \%)$.

Based on the patient triage category, different triangular distributions are used as the service time distributions of registration, triage and diagnosis/treatment processes. Patients consume different resources; staff, equipments, cubicles and trolleys depending on their triage category. Most severe cases are admitted to the hospital, which is subject to the availability of ward beds therefore it is beyond the control of ED management. This study focuses only on the processes and resources within the ED.

\subsubsection{Conceptual Model Phase}

A conceptual model of the ED internal processes was built using IDEF0 (Integration Definition for Function Modeling) (Colquhoun, Baines, and Crossley 1993). IDEF0 enhances communication levels between the analyst and the decision maker through modeling decisions, actions, and processes of the underlined system in a hierarchical form. This hierarchical structure keeps the model scope within the boundaries represented by breaking down processes into smaller subfunctions. Such organizational strategy allows the system to be easily refined into more detail until the model is as descriptive as necessary for the decision maker (Kim and Jang 2002). Chest pain process, for example, is one of major processes inside ED (Figure 5).

Chest paint patients have a high priority (High triage category). Triaged patients are sent to either: Area I in high severe cases; Area II in Less severe cases/Insufficient places in Area I; or waiting room in less severe cases/Insufficient places in Area II. Patients in Area I can be either moved to the cardiopulmonary resuscitation (CPR) room for intensive care and assessment or to the assessment 


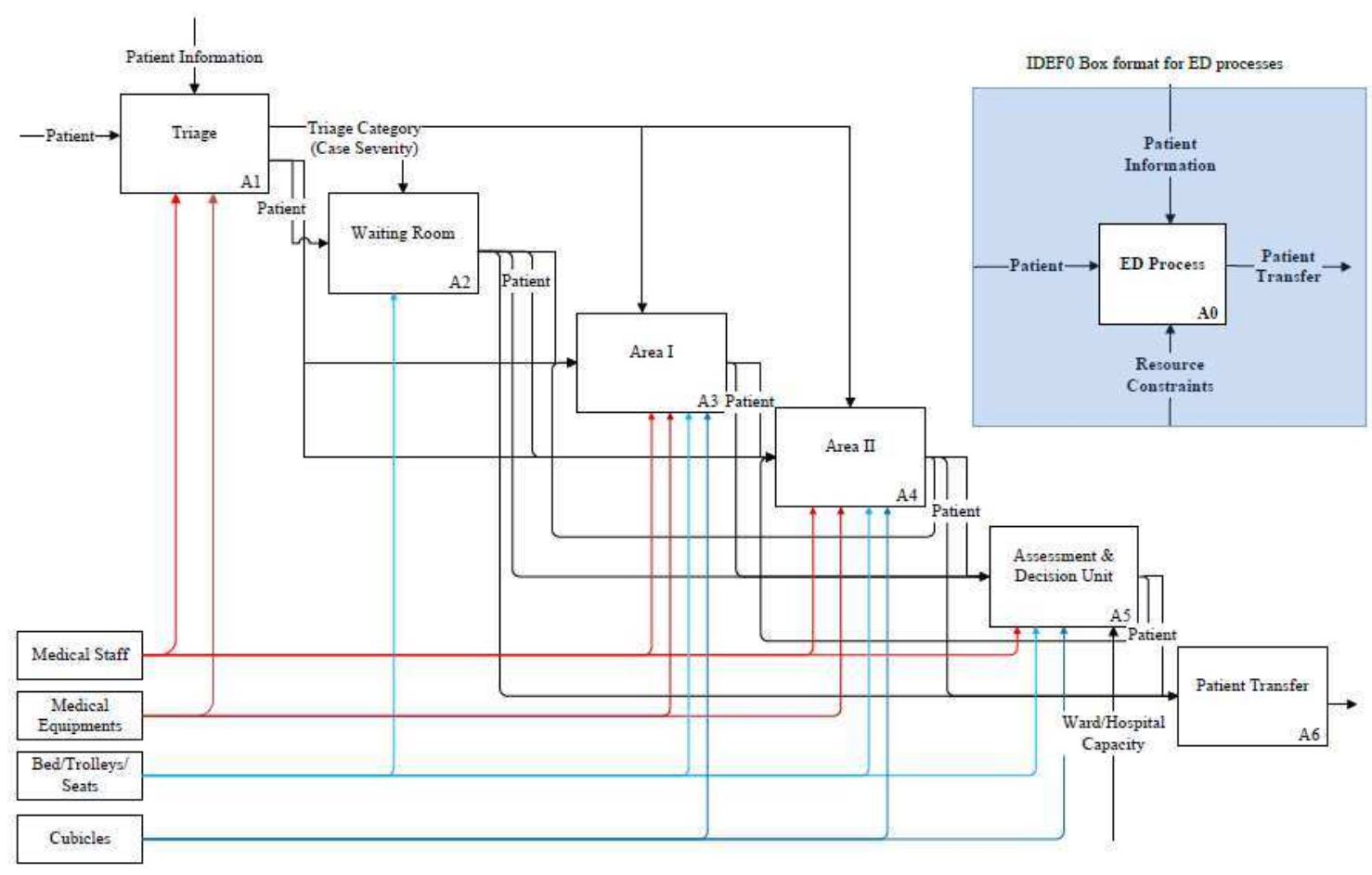

Figure 5: Patient and information flow in chest pain process using IDEF0.

and decision unit where a decision about the patient is taken either to be hospitalized (warded), go home, or go to Area I and II for further treatment and assessment.

\subsection{ED Performance Objectives and Measures}

The proposed BSC includes three main perspectives; patient, ED processes, and training and development (Figure 6). The patient perspective includes patient satisfaction as an objective. The main objective in the ED processes perspective is to maximize the ED efficiency which is driven by maximizing layout efficiency, maximizing patient throughput, maximizing ED productivity, and maximizing resources' utilization. Measures at particular areas such as triage and diagnosis areas and particular types of resources such as doctors, nurses, and X-Ray are also presented. Upgrading staff skills and staff satisfaction are important objectives that can drive better staff utilization are listed at the training and development perspective.

\section{RESULTS AND DISCUSSION}

The early detection of modeling and implementation errors reduces the model development cycle time and increases the confidence in the simulation model results. Based on this premises, the verification and validation were carried out all the way through the development phases of the ED simulation model based on the proposed procedure by Rabe et al. (2009). After each model development phase, the model was verified and validated with respect to other previously completed phases. For example, the results of model construction phase (Figure 4) is verified with respect to the conceptual model phase results and with the problem formulation phase. This cycle of verification and validation is adopted until the final results of simulation model are conducted. The warm-up period time found to be two weeks, and every simulation experiment was run for a period of one month. The simulation settings of the base scenario "as-it-is situation" is shown in Table 1. Experimentation analysis of base scenario results with respect to waiting time, patient cycle time, resource utilization, and ED Productivity measures are shown in Table 2. 
Ismail, Abo-Hamad and Arisha

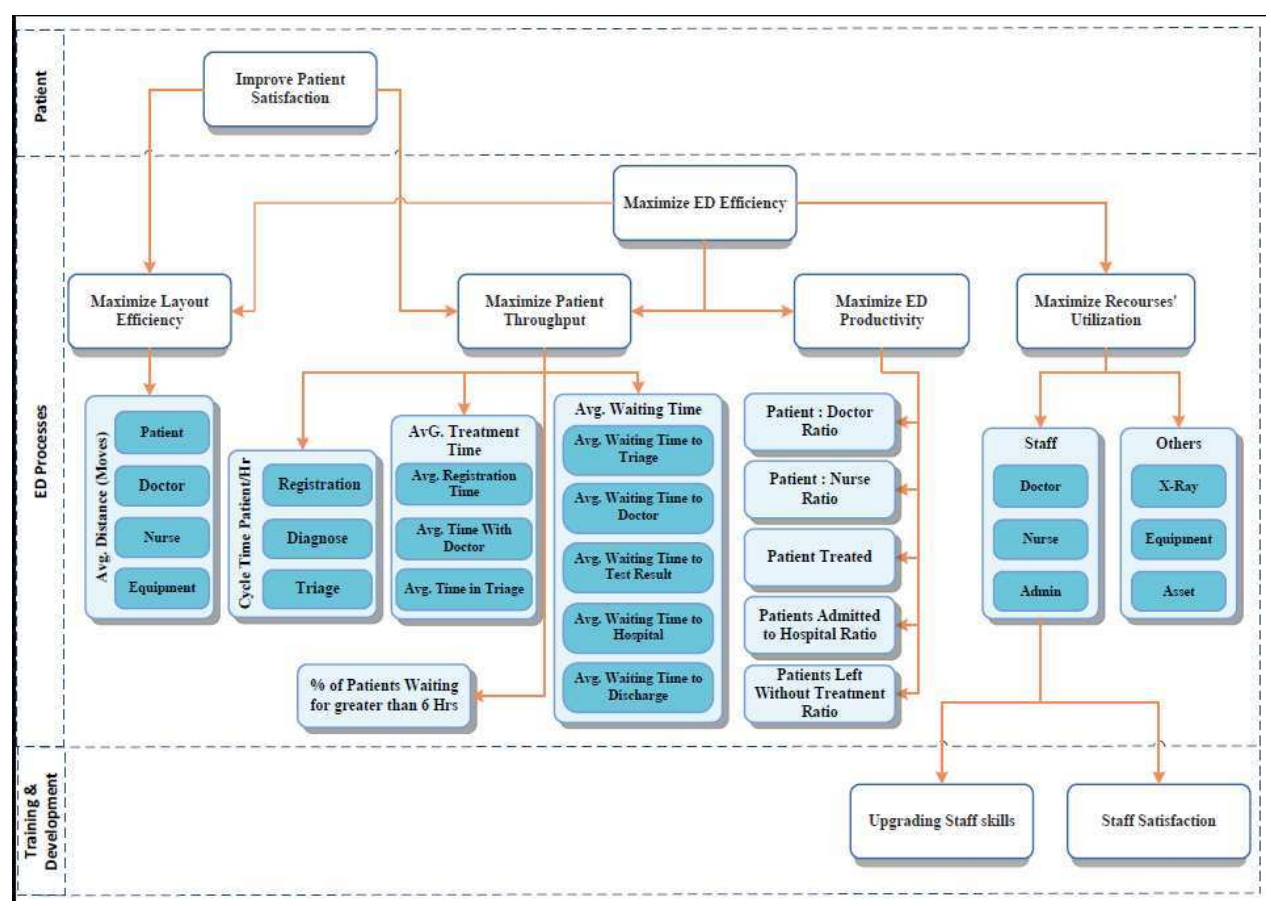

Figure 6: The Proposed BSC for the ED.

Table 1: Simulation model settings for base scenario.

\begin{aligned} & \hline Waiting room capacity 40 patients \\ & \hline Nurses allocated for treatment areas (inside nurse) 8 Nurses \\ & Doctors available 8 Doctors \\ & Number of Registration staff 2 \\ & Number of available Triage Nurse 2 Nurses \\ & Advanced Nurse Practitioner (ANP) 2 Nurses \\ & Respiratory Nurse 1 Nurse \\ & CPR room nurse (resus nurse) 1 Nurse \\ & Percentage of patient arrive via ambulance $20 \% \\ &$ Percentage of self-arriving patient $80 \% \\ &$\hline\end{aligned}

The analysis of waiting time shows a bottleneck at triage area (53\% of total average waiting time). The average utilization rate of staff is between 59\% and 76.3\% for doctors and nurses (Figure 7).

On the other hand, utilization rates of the respiratory nurse (13.4\%) and the resus nurse $(55.5 \%)$ were slightly lower. This shows a bottleneck in resource allocation inside the ED. The third bottleneck is drawn from the analysis of ED productivity results namely, capacity planning. This is noticed as, roughly, $14 \%$ of all patients are expected to leave the ED without treatment, which is directly related to the capacity of ED waiting room. In view of this analysis, three scenarios (Table 3 ) are set for simulation experiments in order to examine the impact of these bottlenecks on ED performance.

Adding a new triage nurse (scenario 1) resulted in a significant drop of waiting time of patients to be triaged. However, this created extra pressure on another area inside the ED (Figure 8).

The average waiting time is reduced when waiting room capacity is increased (scenario 2) compared to scenario 1 and ED productivity is slightly increased. However, the waiting time tends to be fluctuated at different treatment areas. Training and dynamic staff allocation (scenario 3) sounds more appealing to decision makers. This is due to the budget constraints that cannot be met when implementing specific scenarios (i.e. scenario 1 or scenario 2). Moreover, dynamic re-allocation of resources is more convenient in dynamic complex environment such as ED. The waiting time in scenario 3 is significantly improved relative to the base scenario and the other two scenarios. In contrast to the 
Table 2: Base scenario results indicating waiting time measured by hours.

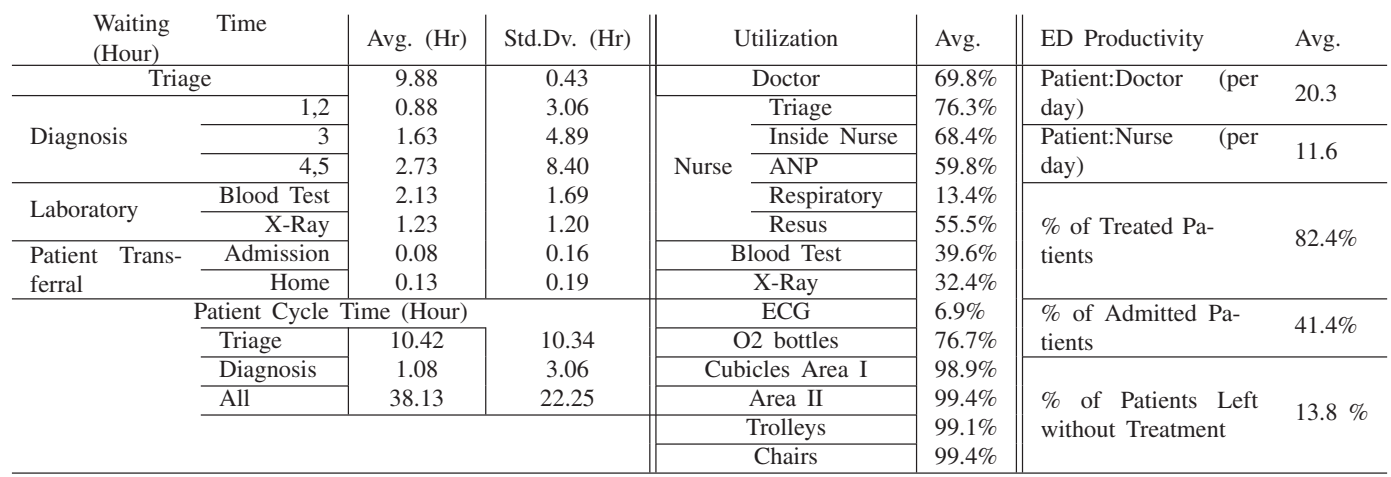

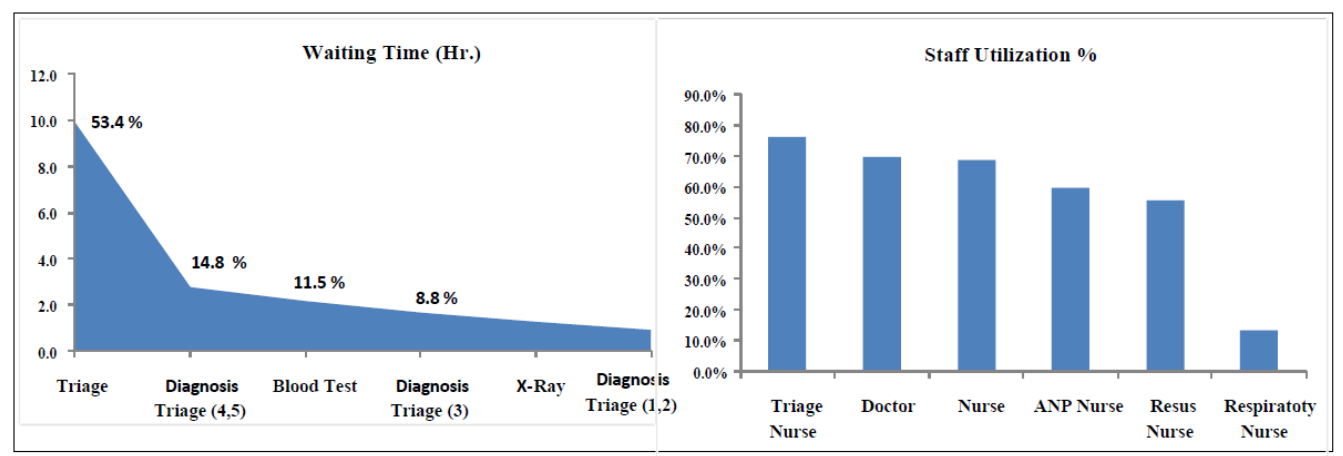

Figure 7: Base scenario result analysis for waiting time and staff utilization .

fluctuation of waiting time in scenario 2 , the average patient waiting time is fairly distributed across all areas of ED. In addition, a noticeable improvement of the ED productivity can be seen as the percentage of patient left without treatment is reduced to only $2 \%$ which means a decrease by almost $100 \%$ compared to the base scenario (Figure 9).

Finally, the utilization of the trained nurses (respiratory nurse and resus nurse) are increased to $85 \%$ and $65 \%$ respectively. In this way, a balanced utilization of medical staff is achieved (Figure $10)$.

\section{CONCLUSION}

At Emergency Department (ED) in hospitals, decision making processes are challenged by high levels of complexity, dynamics, and uncertainty. Employing Balanced Scorecard (BSC) as a performance management framework plays an important role in communicating strategy-linked objectives and ac-

Table 3: Description of three proposed scenarios.

\begin{tabular}{lll}
\hline & Type & Description \\
\hline Scenario 1 & $\begin{array}{l}\text { Nurse Recruitment } \\
\text { Capacity Expansion }\end{array}$ & $\begin{array}{l}\text { Adding a new triage nurse } \\
\text { Expanding waiting room capacity by 10 seats }\end{array}$ \\
Scenario 3 & $\begin{array}{l}\text { Training and Dynamic re- } \\
\text { source Allocation }\end{array}$ & $\begin{array}{l}\text { Train respiratory nurse so that s(he) can act as triage } \\
\text { nurse at peak times. Dynamic allocation of Resus } \\
\text { nurse to be engaged with other nurses in other } \\
\text { treatment areas }\end{array}$ \\
\hline
\end{tabular}




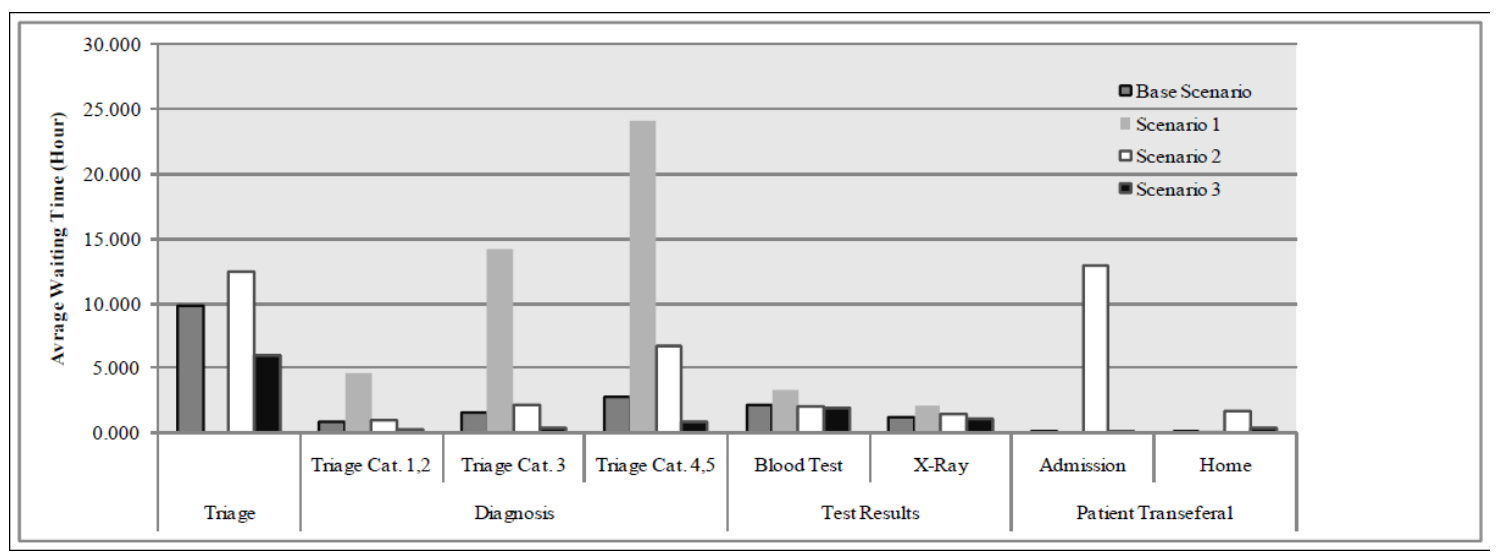

Figure 8: Waiting time results of scenario 1,scenario 2, and scenario 3.

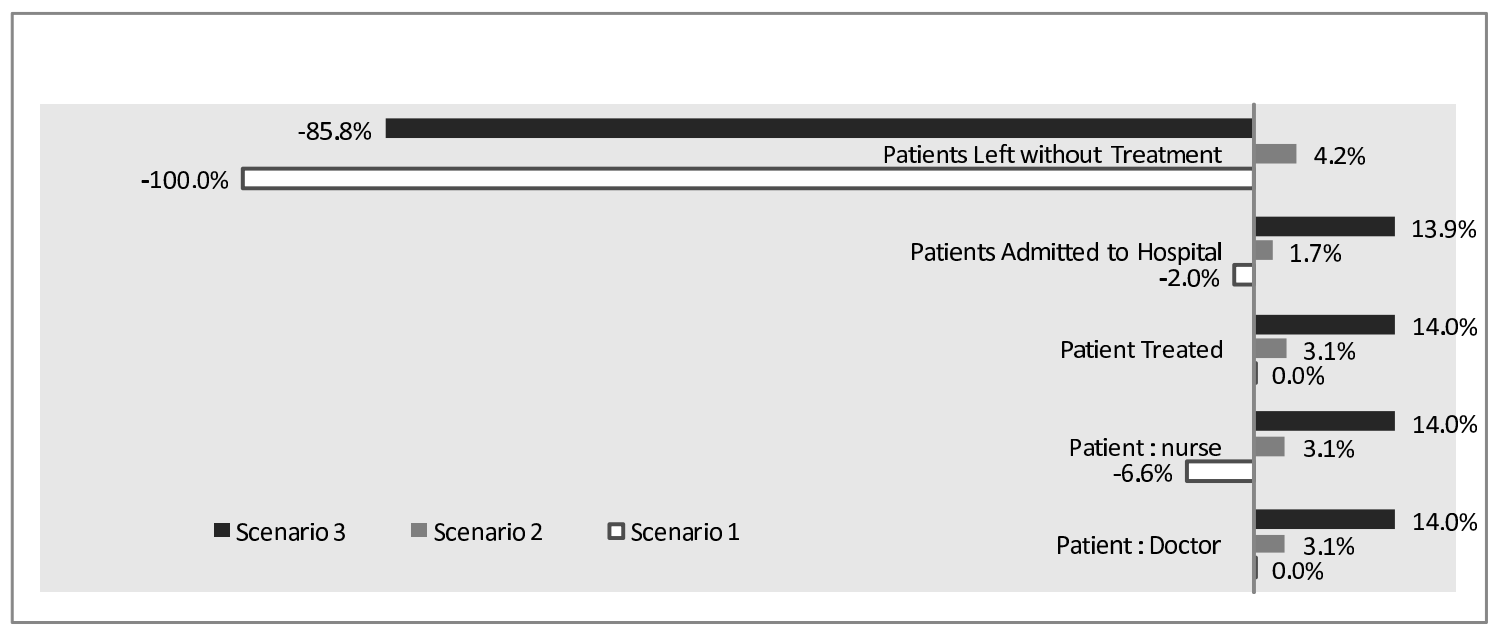

Figure 9: ED productivity results of sceneries 1,scenario 2, and scenario 3.

tions between decision makers and other staff, monitoring achievements, and driving related corrective actions. Though this is a fundamental step in leading different staff groups toward an added-value strategy and encouraging continual improvements and innovation. Nevertheless, BSC as a stand-alone tool has limitations in planning and analyzing activities. On the other hand, simulation modeling approach has robust records and capabilities of evaluating and forecasting system performance to support planning. Integrating BSC and simulation modeling in one framework will have many advantages, for example:

- It provides significant insights at different perspectives of performance measurement.

- Planning targets and initiatives are carried out more rationally and more precisely with less risk in implementation. This is a crucial element in healthcare systems.

- Implementing this methodology might encourage the use of simulation among managers and other staff. That will definitely help in reducing risks and predicting the impact of new strategies before implementing them.

This paper presents a real-world case study of an emergency department of one of the leading hospitals in the Republic of Ireland. Performance scorecard of the ED is designed to consider three main perspectives and objectives. Integrating the proposed BSC with simulation has created a tool that can be used to evaluate and analyze the department performance. The analysis of as-it-is scenario identified three observations; high waiting time at triage area, poor utilization at some treatment areas, 


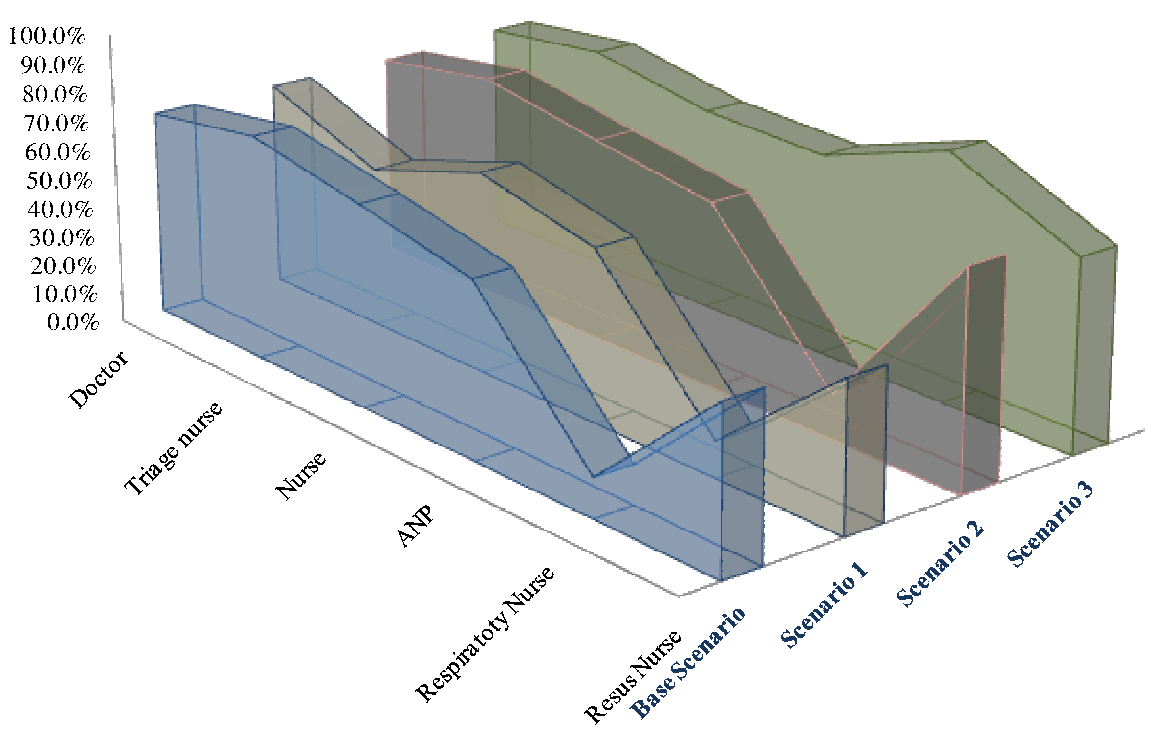

Figure 10: Resource utilization in all scenarios.

and considerable record of patients left the hospital without treatment. Results show the potential of the integrated framework and has reflected on potential strategies for improvement.

\section{ACKNOWLEDGEMENTS}

The authors wish to thank Mater University Hospital for their support of the project. Much gratitude to Ms. Nuala King, Mr. John McInerney, and the CEO's board of Mater hospital. The authors would like also to thank their colleagues John Crowe and Ayman Tobail for their contribution in the simulation modeling phase.

\section{REFERENCES}

Arisha, A., and P. Young. 2004. Intelligent simulation-based lot scheduling of photolithography toolsets in a wafer fabrication facility. In Proceedings of the 2004 Winter Simulation Conference, ed. R. G. Ingalls, M. D. Rossetti, J. S. Smith, and B. A. Peters, 1935-1942. Austin, Texas: Institute of Electrical and Electronics Engineers, Inc.

Centeno, M. A., R. Giachetti, R. Linn, and A. M. Ismail. 2003. A simulation-ILP based tool for scheduling ER staff. In Proceedings of the 2003 Winter Simulation Conference, ed. S. Chick, P. J. Snchez, D. Ferrin, and D. J. Morrice, 1930-1938. Austin, Texas: Institute of Electrical and Electronics Engineers, Inc.

Colquhoun, G., R. Baines, and R. Crossley. 1993. A state of the art review of IDEF0. International Journal of Computer Integrated Manufacturing 6 (4): 252-264.

HSE 2007. National plan 2007. Available via <www.hse.ie/eng/publications/corporate/National_Service_Plan_2007.pdf [accessed September 14, 2009].

HSE 2008. Health service executive corporate plan 2008-2011. Available via <www. lenus.ie/hse/bitstream/10147/51253/1/HSECorporate_Plan_2008_-_2011.pdf [accessed October 6, 2009].

HSE 2009. Corporate performance measurement 2009: Report against the corporate plan 2008-2011, January - June 2009. Available via <www.lenus.ie/hse/bitstream/10147/85402/1/ReportAgainst heCorporatePlan2008[accessed December 3, 2009]. 
Huang, S., P. Chen, M. Yang, W. Chang, and H. Lee. 2004. Using a balanced scorecard to improve the performance of an emergency department. Nursing economic \$ 22 (3): 140-146.

Kaplan, R., and D. Norton. 1992. The balanced scorecard: measures that drive performance. Harvard Business Review:71-79.

Kaplan, R., and D. Norton. 2001. Transforming the balanced scorecard from performance measurement to strategic management: Part I. Accounting Horizons 15 (1): 87-104.

Kim, S., and K. Jang. 2002. Designing performance analysis and IDEF0 for enterprise modelling in BPR. International Journal of production economics 76 (2): 121-133.

McCaig, L. F., and C. W. Burt. 2004. National hospital ambulatory medical care survey: 2002 emergency department summary. Advance Data 340:1-34.

Miller, M., D. Ferrin, and J. Szymanski. 2003. Simulating six sigma improvement ideas for a hospital emergency department. In Proceedings of the 2003 Winter Simulation Conference, ed. S. Chick, P. J. Snchez, D. Ferrin, and D. J. Morrice, 1926-1929. Austin, Texas: Institute of Electrical and Electronics Engineers, Inc.

Rabe, M., S. Spieckermann, and S. Wenzel. 2009. Verification and validation activities within a new procedure model for $\mathrm{v} \& \mathrm{v}$ in production and logistics simulation. In In Proceedings of the 2009 Winter Simulation Conference, ed. M. D. Rossetti, R. R. Hill, B. Johansson, A. Dunkin, and R. G. Ingalls, 2509-2519. Austin, Texas: Institute of Electrical and Electronics Engineers, Inc.

Richardson, D. B. 2006. Increase in patient mortality at 10 days associated with emergency department overcrowding. Medical Journal of Australia 184 (5): 213-216.

Schneider, S., F. Zwemer, A. Doniger, R. Dick, T. Czapranski, and E. Davis. 2008. Rochester, New York: a decade of emergency department overcrowding. Academic Emergency Medicine 8 (11): $1044-1050$.

Sinreich, D., and Y. N. Marmor. 2004. A simple and intuitive simulation tool for analyzing emergency department operations. In Proceedings of the 2004 Winter Simulation Conference, ed. R. G. Ingalls, M. D. Rossetti, J. S. Smith, and B. A. Peters, 1994-2002. Austin, Texas: Institute of Electrical and Electronics Engineers, Inc.

Spry, C. W., and M. A. Lawley. 2004. Evaluating hospital pharmacy staffing and work scheduling using simulation. In Proceedings of the 2005 Winter Simulation Conference, ed. M. E. Kuhl, N. M. Steiger, F. B. Armstrong, and J. A. Joines, 2256-2263. Austin, Texas: Institute of Electrical and Electronics Engineers, Inc.

Swisher, J., and S. Jacobson. 2002. Evaluating the design of a family practice healthcare clinic using discrete-event simulation. Health Care Management Science 5 (2): 75-88.

Takakuwa, S., and H. Shiozaki. 2004. Functional analysis for operating emergency department of a general hospital. In Proceedings of the 2004 Winter Simulation Conference, ed. R. G. Ingalls, M. D. Rossetti, J. S. Smith, and B. A. Peters, 2003-2011. Austin, Texas: Institute of Electrical and Electronics Engineers, Inc.

Thorwarth, M., A. Arisha, and P. Harper. 2009. Simulation model to investigate flexible workload management for healthcare and servicescape environment. In In Proceedings of the 2009 Winter Simulation Conference, ed. M. D. Rossetti, R. R. Hill, B. Johansson, A. Dunkin, and R. G. Ingalls, 1946-1956. Austin, Texas: Institute of Electrical and Electronics Engineers, Inc.

Voelker, K., J. Rakich, and G. French. 2001. The balanced scorecard in healthcare organizations: a performance measurement and strategic planning methodology. Hospital topics 79 (3): 13-24.

Zelman, W., G. Pink, and C. Matthias. 2003. Use of the balanced scorecard in health care. Journal of Health Care Finance 29 (4): 1-16.

\section{AUTHOR BIOGRAPHIES}

KHALED ISMAIL, M.Sc. is a researcher in the 3S group (Research unit in DIT specialized in complex systems simulation and optimization). He received his B.Sc. degree specialized in Industrial Engineering and Production from Zagazig University and his M.Sc. degree specialized in Industrial Engineering from the American University in Cairo (AUC). Currently, he is a $\mathrm{PhD}$ student at the Dublin Institute of Technology (DIT). He has published a number of journal and conference papers in the area of modeling using Artificial Neural Network (ANN) and Healthcare. He has over 8 years experience in Corporate Performance Management (CPM) and Quality Management. His research interests include; Corporate Performance Management, Simulation Modeling, and Artificial Intelligence. His email address is <khaledauc@yahoo.com>. 
WALEED ABO-HAMAD, M.Sc. is a researcher in the 3S group (Research unit in Dublin Institute of Technology (DIT) specialized in complex systems simulation and optimization). He joined the $3 \mathrm{~S}$ group in 2008 having spent four years as a senior researcher in Cairo University-Egypt where he received his B.Sc. and M.Sc. degrees in Computer Science. Waleed has been an active member of the support team of Avicenna Knowledge Center (AKC) project funded by the European Commission and UNESCO-Paris. Currently, he is a PhD student at DIT. His research interests include Modeling and Simulation, Optimization, Computational Intelligence, Machine Learning and Cooperative Intelligent Systems. His email address is <waleed.abohamad@dit.ies.

AMR ARISHA, Ph.D. is a Manager of the 3S Group (Research unit in DIT specialized in complex systems simulation and optimization) and a lecturer in School of Management in Dublin Institute of Technology. He Joined DIT in 2005 having spent five years as a senior researcher in Dublin City University. Intel-Ireland has sponsored his research from 2000 - 2005. He received his Ph.D. in Industrial Engineering from Dublin City University (DCU). Dr. Arisha has published many journal and international conference articles in the area of manufacturing systems simulation and scheduling. His research interests include analysis and optimization of complex dynamic systems in manufacturing and service industries using stochastic simulation modeling, and optimization techniques. His research also includes Supply Chain Management, Operations Excellence, Project Management, Virtual Reality applications in Business Process Analysis, and Optimization for Process Improvement. He is a member in IIE, IMECH, IEI, ESE, ORS, IEEE and ASME. His e-mail address is <amr . arisha@dit.ie>. 